\title{
Geographical distribution and spatio-temporal patterns of hospitalization due to dengue infection at a leading specialist hospital in Malaysia
}

\author{
Gary K.K. Low, ${ }^{1}$ Panayotis Papapreponis, ${ }^{2}$ Ridzuan M. Isa, ${ }^{3}$ Seng Chiew Gan, ${ }^{1}$ Hui Yee Chee, ${ }^{4}$ \\ Kian Keong Te, ${ }^{1}$ Nadia M. Hatta ${ }^{1}$ \\ ${ }^{1}$ Department of Population Medicine, Faculty of Medicine and Health Sciences (FMHS), University Tunku \\ Abdul Rahman (UTAR), Selangor, Malaysia; ${ }^{2}$ Laboratory of Microbiology and Immunology, Cancer \\ Hospital of Thessaloniki, Greece; ${ }^{3}$ Emergency and Trauma Department, Hospital Ampang, Ampang, \\ Selangor, Malaysia; ${ }^{4}$ Faculty of Medicine and Health Sciences, University Putra Malaysia, Selangor, \\ Malaysia
}

\begin{abstract}
Increasing numbers of dengue infection worldwide have led to a rise in deaths due to complications caused by this disease. We present here a cross-sectional study of dengue patients who attended the Emergency and Trauma Department of Ampang Hospital, one of Malaysia's leading specialist hospitals. The objective was to search for potential clustering of severe dengue, in space and/or time, among the annual admissions with the sec-
\end{abstract}

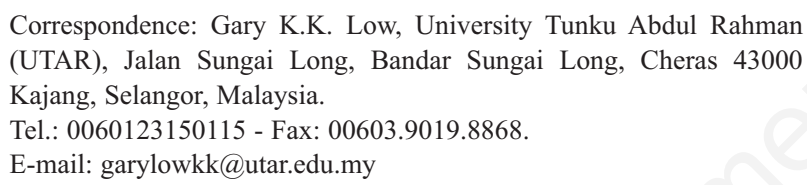

Key words: Severe dengue; Clusters; Mapping; Outbreak; Epidemics; Malaysia.

See online Appendix for an additional Table.

Acknowledgements: the authors would like to thank the General Director of Health Malaysia for his permission to publish this article. Tok Zhen Yu and Daniel Lee for data collection.

Contributions: the authors contributed equally.

Conflict of interest: the authors declare no potential conflict of interest.

Funding: this study was supported by the University Tunku Abdul Rahman Strategic Research Fund (UTARSRF) programme 2014$\mathrm{C} 1 / 010$.

Received for publication: 25 October 2017.

Revision received: 19 January 2018.

Accepted for publication: 19 January 2018.

CCopyright G.K.K. Low et al., 2018

Licensee PAGEPress, Italy

Geospatial Health 2018; 13:642

doi:10.4081/gh.2018.642

This article is distributed under the terms of the Creative Commons Attribution Noncommercial License (CC BY-NC 4.0) which permits any noncommercial use, distribution, and reproduction in any medium, provided the original author(s) and source are credited. ondary objective to describe the spatio-temporal pattern of all dengue cases admitted to this hospital. The dengue status of the patients was confirmed serologically with the geographic location of the patients determined by residency, but not more specific than the street level. A total of 1165 dengue patients were included in the analysis using SaTScan software. The mean age of these patients was 27.8 years, with a standard deviation of 14.2 years and an age range from 1 to 77 years, among whom 54 (4.6\%) were cases of severe dengue. A cluster of general dengue cases was identified occurring from October to December in the study year of 2015 but the inclusion of severe dengue in that cluster was not statistically significant $(\mathrm{P}=0.862)$. The standardized incidence ratio was 1.51. General presence of dengue cases was, however, detected to be concentrated at the end of the year, which should be useful for hospital planning and management if this pattern holds.

\section{Introduction}

An estimated 390 million dengue infections occur annually all over the world (Bhatt et al., 2013). The World Health Organization (WHO) gives the figure of 500000 people with severe dengue requiring hospitalization each year, about $2.5 \%$ of whom die (WHO, 2016). Various studies have investigated the geographical distribution of dengue outbreaks in countries where the disease is endemic. (Chang et al., 2009; Anno et al., 2015; Rotela et al., 2017; Hafeez et al., 2017). A few recent studies have also been conducted in Malaysia to evaluate the spatial pattern of the disease (Er et al., 2010; Hassan et al., 2012; Ling et al., 2014). However, none of the studies focused on potential clustering of severe dengue cases as a way of limiting transmission.

The epidemiological pattern of dengue transmission has been studied for a long time and statistical modelling has been developed to predict future outbreaks (Louis et al., 2014). Yet, public health interventions have not succeeded in interrupting transmission of the disease. Interventions such as fogging and larvae inspection in large areas, e.g., all endemic parts of Malaysia, would require enormous manpower. However, the identification of clusters of severe dengue cases may help focusing public health interventions and thus make them more cost-effective. This approach may also provide predictive information on the specific risk factors, which depend on variations of the geographical landscape. Insights on severe dengue cluster patterns could be gained through the study of hospital admissions of dengue patients.

Understanding the development of dengue outbreaks 
throughout the year is important for hospital planning and management, as appropriate resources are usually budgeted for and allocated annually from the central governing body, i.e. the Ministry of Health. Hence, the primary objective of this study was to investigate the occurrence of severe dengue clustering, in space and/or time during one year. The secondary objective was to describe the spatio-temporal pattern of all dengue cases admitted to the hospital in the same year. It was felt to be useful to carry out the work at Ampang Hospital, a leading specialist hospital located in an area endemic for dengue near Kuala Lumpur, the capital of Malaysia.

\section{Materials and Methods}

\section{Study area and population investigated}

This is a cross-sectional study of dengue patients attending the Emergency and Trauma Department of Ampang Hospital between February and December 2015. All data regarding dengue patients were obtained via the department's census record, which is the most reliable and complete source of data because all patients have to be registered in this department before being admitted or discharged. The Ampang Hospital provides health care services in
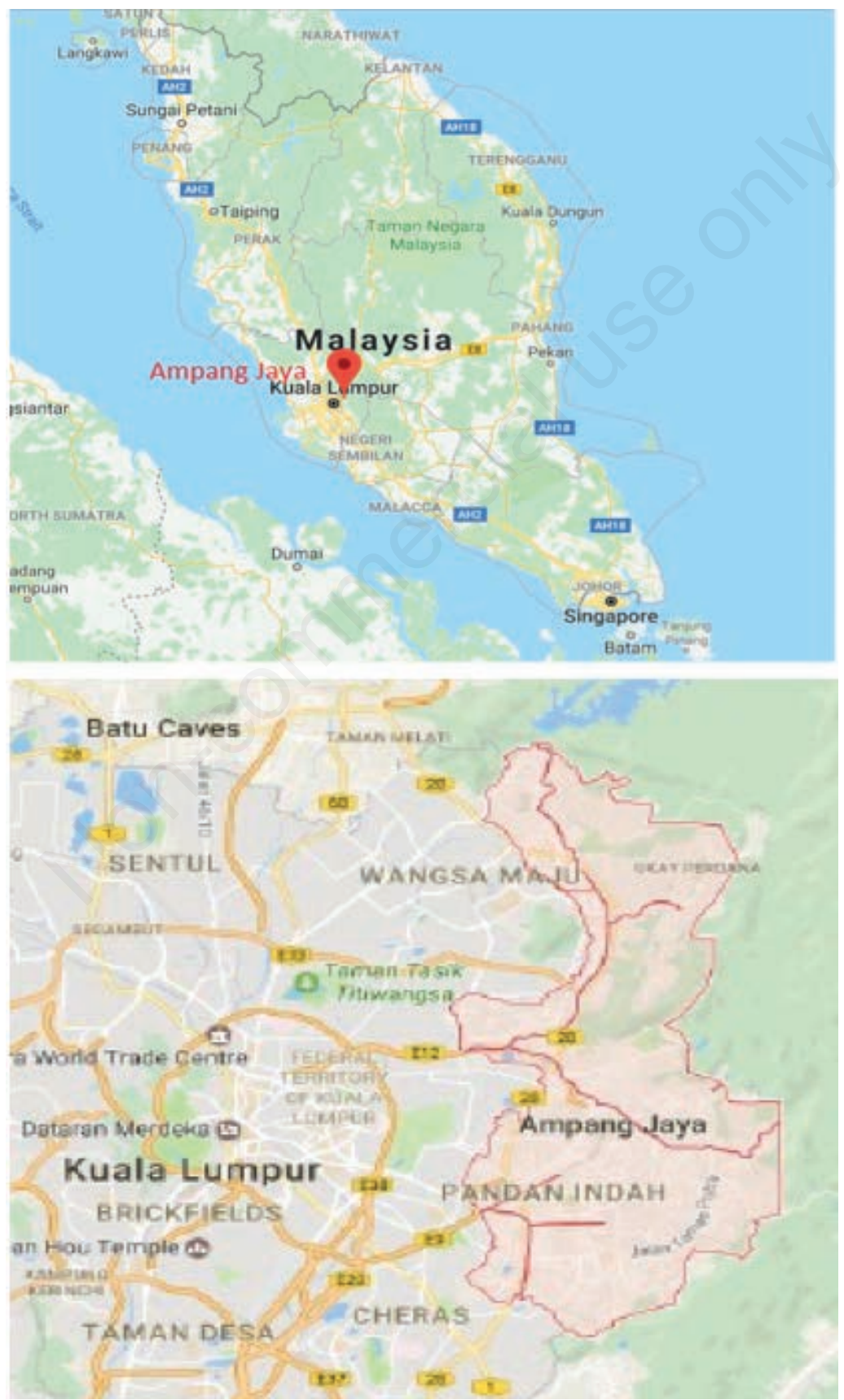

Figure 1. Ampang Jaya. Study area in pink with boundaries in red. 
Ampang Jaya, a sub-district of Hulu Langat. The Ampang Jaya boundary and location is depicted in Figure 1. All cases beyond this boundary were excluded. Sporadic cases found outside Ampang Jaya were excluded because they are usually treated by other hospitals in surrounding subdistricts. Other excluded cases were people with addresses in other states of Malaysia or coming from other countries. All patients included in this study were confirmed positive for dengue infection, either due to the presence of dengue IgM antibodies or NS1 antigen or both. The enzyme-linked immunosorbent assay (ELISA) was used by the hospital laboratory to detect dengue IgM in the blood of patients suspected to be infected. The immunochromatographic NS1 Antigen rapid kit was employed in the Emergency Department and Medical Ward. (WHO/TDR, 2012) Patients were excluded if there was no positive dengue IgM or NS1 antigen test, or an equivocal result of the dengue IgM test had been obtained indicating uncertainty of status. The final diagnosis accepted was based on the clinical practice guidelines recommended by WHO in 2009 (WHO/TDR, 2012). The WHO 2009 classification sorts the disease into three subgroups according to the severity of the infection: dengue without warning sign, dengue with warning signs and severe dengue, which is further subcategorised into severe plasma leakage, severe bleeding and severe organ involvement. Only two diagnoses were utilized in this study: severe dengue and non-severe dengue (with and without warning signs).

Demographic data were extracted along with the corresponding home addresses, which indicated the geographic location of the patients. The longitude and latitude of these addresses were determined using Google Maps (2016 version). However, to ensure confidentiality, the addresses were not followed further than the street level. Therefore, the coordinates obtained using the addresses were only approximations of the exact locations. Addresses not found via Google Maps were obtained by travelling to their physical location and geocoded on site using Google Maps.

In Malaysia, garden is an area with a boundary somewhere between the street level and the district level. A total of 42 centroids, either representing a garden or a group of gardens, were coded. When areas had a particularly small geographical space, the centroids were coded together with adjacent areas. The list of the centroids and the corresponding geographical coordinates are tabulated in the Appendix.

\section{Statistical analysis}

Potential spatio-temporal clustering was investigated with space and time scan statistics using SaTScan software, v. 9.3 (Kulldorff, 2010). Briefly, SaTScan applies a circular scanning window centred on the geographic constituencies of the area under investigation (thus creating the centroid), which is allowed to gradually increase in size. Depending on the number of observed and expected cases within a centroid, i.e. window frame, as compared with the outside, a cluster of a disease may be pronounced. The decision of the existence of a cluster is made on the basis of a likelihood ratio test.

In this study, two statistical models were applied: the Bernoulli model and the space-time permutation model (Kulldorff, 2010). In the former, we investigated potential spatio-temporal clustering of severe dengue in relation to the spatio-temporal distribution of total dengue events. Severe dengue events were classified as cases and the non-severe dengue events as controls. The space-time permutation model was used to address the secondary objective of our study, i.e. the observed spatio-temporal distribution of all dengue infections (both severe and non-severe) was compared to what would have been expected if the spatial and temporal distribution were independent to each other (i.e. without space-time interaction). This model included covariates such as age, gender and race that were used for adjustments.

In the spatio-temporal analyses, we set the range of $200 \mathrm{~m}$ as the maximum size of the spatial window radius and 14 days as the maximum temporal size. These parameters were set in accordance with the definition of dengue clusters in Malaysia (Malaysian Remote Sensing Agency, 2014). The mapping software of the epidemiological package of Epi Info 7 (Dean et al., 2011) was used to display results in the form of maps. Google map was used to display the boundaries of the regions under investigation. The level of significance for all analyses was set at $<0.05$.

\section{Results}

The total number of dengue patients recorded by the Ampang Hospital during 2015 were 2379. Among them, 105 cases (4.4\%) were severe dengue cases. There were 340 (14.3\%) missing data. After excluding 874 cases originating outside the study area and the 340 missing data, our study group consisted of 1165 dengue patients, among whom 54 (4.6\%) were classified as severe.

The mean age of the patients (ranging in age from 1 to 77 years) was 27.8 years with a standard deviation (SD) of 14.16. Upon stratification into severe and non-severe dengue, the mean age was 31.7 years $(\mathrm{SD}=14.33)$ and 27.6 years $(\mathrm{SD}=14.13)$, respectively. Information concerning gender, nationality and race, including laboratory confirmation and subclassification of severe dengue, is tabulated in Table 1. Most patients admitted to the hospital (100 patients) came from Pandan Indah. Each centroid code

Table 1. Included study subjects.

\begin{tabular}{lccc}
\hline Attribute & $\begin{array}{c}\text { Number of } \\
\text { patients (\%) }\end{array}$ & P-value* \\
& Non-SD** & SD*** & \\
Gender & $696(59.7)$ & $28(2.4)$ & \\
Male & $415(35.6)$ & $26(2.2)$ & 0.11 \\
Female & Non-SD & SD & \\
Nationality and race & $590(50.6)$ & $28(2.4)$ & \\
Malay & $191(16.4)$ & $11(0.9)$ & \\
Chinese & $67(5.8)$ & $2(0.2)$ & \\
Indian & $11(0.9)$ & $1(0.1)$ & \\
Other Malaysians & $252(21.6)$ & $12(1.0)$ & 0.88 \\
Non-Malaysians & & & \\
\hline Laboratory confirmation & $139(11.9)$ & \\
NS1 Antigen & $903(77.5)$ & \\
Dengue IgM & $122(10.5)$ & \\
Both NS1 Ag and dengue IgM & $1(0.1)$ & \\
Dengue virus genome detection*** & & \\
Sub-classification of severe dengue & $45(83.3)$ & \\
Severe plasma leakage & $1(1.9)$ & \\
Severe bleeding & $6(11.1)$ & \\
Severe organ involvement & $2(3.7)$ & \\
Unspecified & & \\
*Chi-square test; **Severe dengue; *** Laboratory technical details of genome analysis was not available.
\end{tabular}


and population characteristic are tabulated in Table 2. The number of cases stratified by severe and non-severe dengue in each month between February to December 2015 is displayed in Figure 2.

Figure 3 displays the distribution of severe dengue cases among the non-severe ones in the study area. The SaTScan analysis using the Bernoulli model did not identify any severe dengue clusters $(\mathrm{P}=0.862)$, while the space-time permutation model revealed one statistically significant spatio-temporal cluster $(\mathrm{P}<0.001)$, i.e. cluster A centred on centroid 13 with a radius of $1.84 \mathrm{~km}$ which included the six neighbouring centroids $13,8,38$, 9, 40 and 12. The time span of the cluster covered three months (October-December 2015). The standardized incidence ratio (SIR) was 1.89. After adjustment for age, gender and race, cluster A remained statistically significant $(\mathrm{P}<0.05)$ with the same time

Table 2. Population characteristics of each centroid.

\begin{tabular}{|c|c|c|c|c|}
\hline Kampung Tasik Permai & 1 & 30 & 21.2(12.5) & 56.7 \\
\hline Taman Dato Ahmad Razali/Ukay Heights & 2 & 43 & 28.6(11.9) & 79.1 \\
\hline Taman Melur/Taman Saga & 3 & 21 & $33.3(17.3)$ & 57.1 \\
\hline Pandan Indah & 4 & 100 & 27.1(12.1) & 60.0 \\
\hline Taman Komersial Pandan Indah & 5 & 12 & $26.3(10.1)$ & 83.3 \\
\hline Taman Shamelin Perkasa & 6 & 24 & $26.3(8.5)$ & 95.8 \\
\hline Wangsa Maju/Wangsa Melawati & 7 & 7 & $31.6(24.6)$ & 57.1 \\
\hline Pandan Perdana & 8 & 46 & $29.0(13.5)$ & 71.7 \\
\hline Taman Seraya & 9 & 15 & $27.4(13.0)$ & 53.3 \\
\hline Taman Cahaya & 10 & 29 & 28.1(11.4) & 69.0 \\
\hline Ukay Perdana & 11 & 19 & $26.5(14.9)$ & 47.4 \\
\hline Taman Kencana/Taman Lembah Maju & 12 & 25 & $34.8(17.9)$ & 52.0 \\
\hline Taman Cheras Utama/Cheras/Sri Bahtera & 13 & 43 & $30.2(16.5)$ & 74.4 \\
\hline Taman Angsana Hilir/Kampung Berembang/Kampung Perwira Jaya/Desa Pandan & 14 & 36 & $25.0(12.1)$ & 63.9 \\
\hline Kampung Pandan Dalam/Taman Nirwana/Taman Putra Sulaiman & 15 & 69 & 25.2(14.3) & 58.0 \\
\hline Taman Melawati/Taman Permata & 16 & 13 & 27.5(12.2) & 53.8 \\
\hline Taman Saujana Ampang/Taman Mulia & 17 & 28 & 22.4(12.8) & 57.1 \\
\hline Ampang Jaya/Kampung Melayu Tambahan/Taman Uda Jaya & 18 & 20 & $29.0(15.4)$ & 65.0 \\
\hline Kampung Baru Ampang/Taman Sri Merdeka & 19 & 43 & 28.1(12.3) & 55.8 \\
\hline Taman Ampang Mewah/Bandar Baru Ampang & 20 & 44 & $31.0(14.2)$ & 75.0 \\
\hline Pandan Mewah & 21 & 32 & 25.3(13.7) & 56.3 \\
\hline Taman Tasik Tambahan/Taman Sri Raya & 22 & 24 & $23.9(17.1)$ & 66.7 \\
\hline Kampung Ampang Campuran & 23 & 13 & 22.4(15.9) & 69.2 \\
\hline Taman Dagang/Taman Ampang Utama & 24 & 16 & $32.4(16.4)$ & 37.5 \\
\hline Taman Dagang Jaya & 25 & 13 & $28.8(8.8)$ & 53.8 \\
\hline Taman Mega Jaya/Taman Bukit Teratai & 26 & 16 & 27.2(15.2) & 68.8 \\
\hline Kampung Indah Permai/Lembah jaya & 27 & 32 & $22.8(14.2)$ & 56.3 \\
\hline Taman Bukit Indah & 28 & 39 & $32.9(17.3)$ & 56.4 \\
\hline Taman Cheras Indah/Taman Maju Jaya & 29 & 19 & $29.3(12.1)$ & 52.6 \\
\hline Taman Setiawangsa & 30 & 24 & $31.0(14.6)$ & 54.2 \\
\hline Kampung Berembang/Kuala Ampang & 31 & 11 & $29.0(11.5)$ & 54.5 \\
\hline Taman Keramat/AU 1/AU 2 & 32 & 26 & $26.6(15.1)$ & 53.8 \\
\hline AU 3/AU 4/AU 5/Taman Sri Ukay & 33 & 32 & $28.7(12.6)$ & 62.5 \\
\hline Taman Sri Watan/Taman Halaman/Taman Sri Ampang/Taman Bukit Ampang & 34 & 30 & 26.4(16.5) & 70.0 \\
\hline Taman Kosas & 35 & 26 & 28.6(14.6) & 69.2 \\
\hline Bukit Antarabangsa/Taman Bukit Mulia & 36 & 14 & $33.9(17.0)$ & 57.1 \\
\hline Taman Kelab Ukay/Sering Ukay/Taman Ukay Bistari/Zooview/Nusa Tropica & 37 & 13 & $29.0(12.8)$ & 53.8 \\
\hline Taman Bukit Permai/Bukit Pandan & 38 & 18 & $29.9(15.4)$ & 55.6 \\
\hline Taman Muda/Taman Mawar/Taman Putra & 40 & 52 & $24.0(10.9)$ & 71.2 \\
\hline Taman Cempaka/Taman Bakti Ampang & 41 & 13 & $37.6(13.7)$ & 53.8 \\
\hline Taman Pandan Jaya & 42 & 35 & 29.1(16.7) & 42.9 \\
\hline
\end{tabular}

*Standard deviation. 
span, still centred on centroid 13 but now with a radius of $1.73 \mathrm{~km}$ which included the same neighbouring centroids with the exception of centroid 12 (Figure 4). The SIR was 1.51. The characteristics of all clusters are displayed in Table 3.

\section{Discussion}

The occurrence of severe dengue cases followed the same spatial pattern as that of the non-severe dengue cases. This was supported by national statistical reports whereby the case fatality rate remained constant even though the total number of dengue cases was fluctuating between 2001 and 2016 (Malaysian Remote Sensing Agency, 2014). Although no statistically significant cluster of severe dengue cases was found, the secondary objective was successful, which should be useful for hospital planning and management. This concerns the statistically significant spatio-temporal cluster of general dengue infections discovered by the end of the study year. The presence of one or more severe dengue clusters was hypothesized because certain serotypes result in different outcomes of the disease (Soo et al., 2016). Another hypothesis for the presence of severe dengue clusters is that the underlying genetic susceptibility of a population to the virus could play a role in the outcome of the infection (Khor et al., 2011). Since the gene(s) making a person susceptible to severe dengue are hereditary, the possibility for a population to have the same susceptible gene(s)

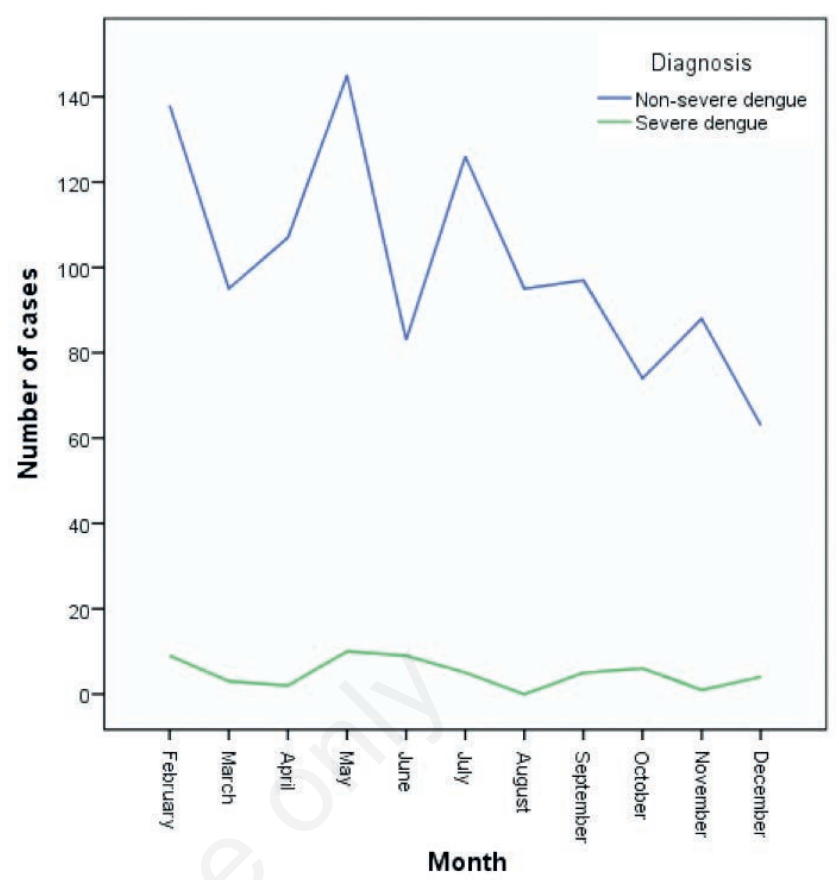

Figure 2. Annual review of the number of dengue cases admitted from Ampang Jaya per month in 2015.

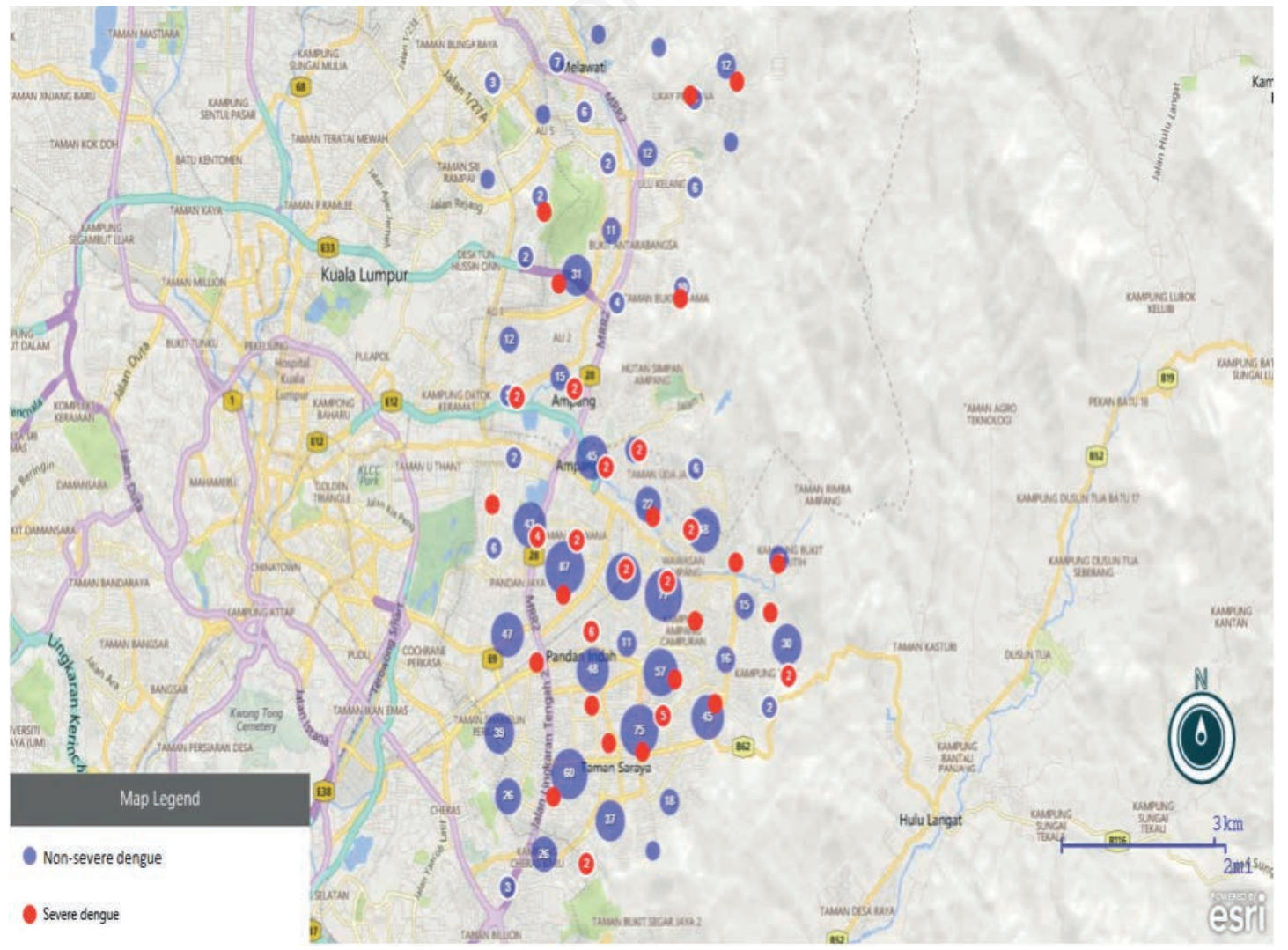

Figure 3. Distribution of severe dengue cases among the non-severe dengue cases. 
increases. That our study failed to identify any such clustering might mean that different serotypes and susceptible genes do not play a significant role with regard to the geographical distribution of severe dengue.

Quite often only a single serotype of the dengue virus is responsible for an outbreak, which could also explain the absence of clustered severe dengue cases. In 2015, dengue serotype 1 was the predominant serotype $(60 \%)$ circulating in Malaysia (WHO, 2015). This could imply that there is a complex host-virus interaction involving many other pathophysiological aspects of the disease with the clinical outcome not solely based on genetic factors (Coffey et al., 2009; Htun et al., 2015). Social health determinants, such as health-seeking behaviour, accessibility to healthcare as well as culture and socioeconomic condition, could all play a role

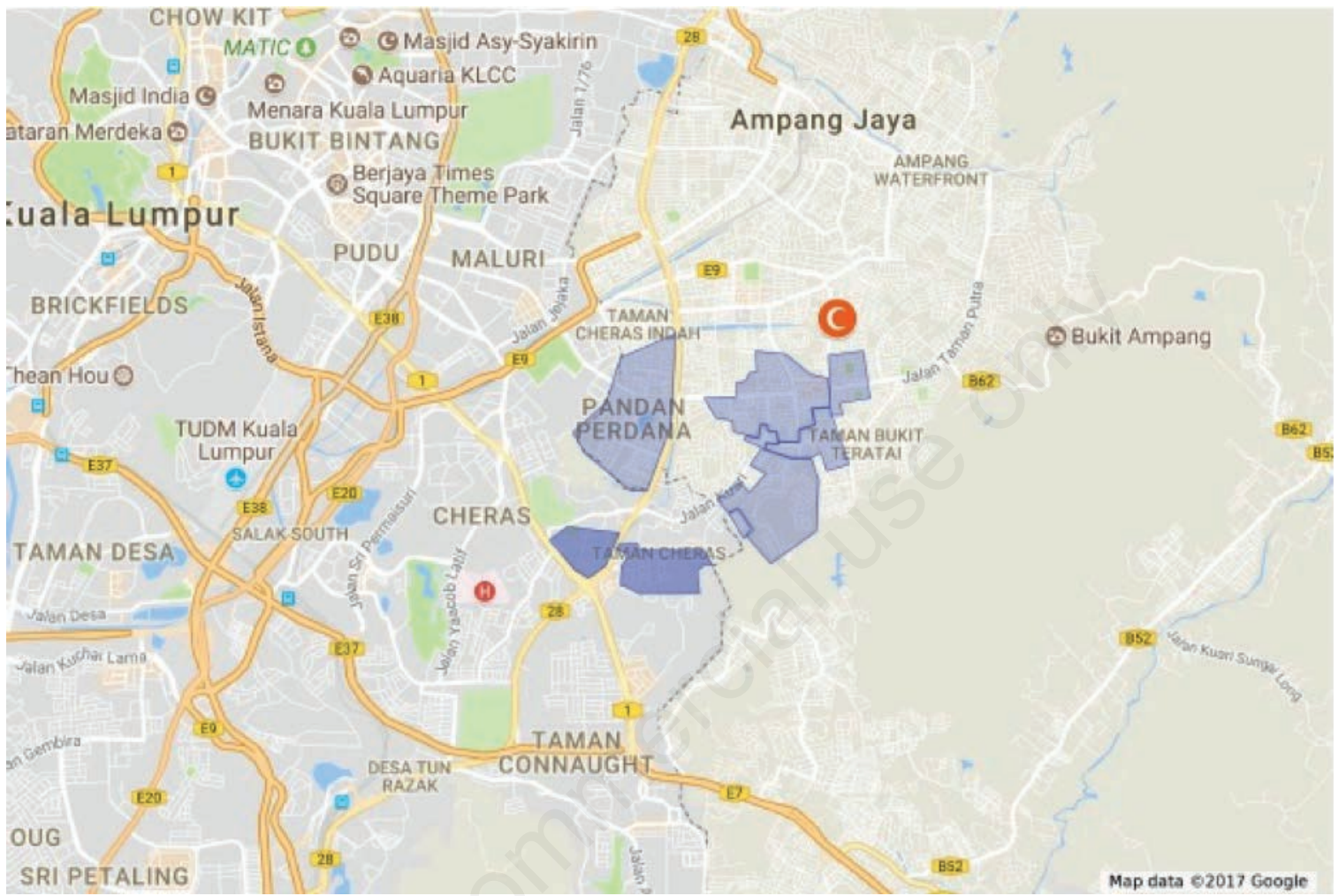

Figure 4. Cluster A with the five neighbouring centroids in relation to the location of Ampang Hospital. Legend: C Ampang Hospital.

Table 3. Characteristics of spatio-temporal clusters in the space-time permutation model.

\begin{tabular}{|c|c|c|c|c|c|c|c|c|}
\hline Cluster & Centroid & Radius (km) & Time span & Number of locations & P-value & Observed cases & Expected cases & SIR* \\
\hline \multicolumn{9}{|c|}{ Unadjusted } \\
\hline A & 13 & 1.84 & October-December & 6 & $<0.001$ & 76 & 40.31 & 1.89 \\
\hline B & 31 & 0.99 & October-December & 2 & 0.093 & 10 & 2.64 & 3.78 \\
\hline $\mathrm{C}$ & 33 & 2.38 & August-September & 5 & 0.136 & 30 & 15.31 & 1.96 \\
\hline D & 35 & 2.43 & February-March & 15 & 0.347 & 118 & 88.78 & 1.33 \\
\hline$E$ & 29 & 0.85 & May & 3 & 0.490 & 21 & 10.18 & 2.06 \\
\hline $\mathrm{F}$ & 22 & 0.00 & December & 1 & 0.996 & 5 & 1.40 & 3.58 \\
\hline \multicolumn{9}{|c|}{ Adjusted (for age, gender and race) } \\
\hline A & 13 & 1.73 & October-December & 5 & $<0.05$ & 68 & 45.03 & 1.51 \\
\hline B & 30 & 0.00 & August & 1 & 0.103 & 7 & 1.86 & 3.76 \\
\hline $\mathrm{C}$ & 31 & 0.99 & October & 2 & 0.160 & 10 & 3.60 & 2.78 \\
\hline $\mathrm{D}$ & 20 & 2.14 & February-April & 16 & 0.326 & 197 & 164.99 & 1.19 \\
\hline$E$ & 29 & 0.85 & May & 3 & 0.954 & 21 & 12.66 & 1.66 \\
\hline $\mathrm{F}$ & 16 & 0.00 & April & 1 & 0.999 & 4 & 1.25 & 3.21 \\
\hline
\end{tabular}

*Standardized incidence ratio. 
in the severity of dengue infection (Carabali et al., 2015). These determinants could lead also to differences in the incidence of severe dengue among dengue-endemic countries. Since our study was limited to a single sub-district, shared traits of social determinants might have played a role in limiting clustering of severe dengue. Furthermore, treatment of dengue infection along with the WHO 2009 case classification (WHO/TDR, 2012) might have reduced the number of severe dengue cases as this approach was used to admit patients who had warning signs (WHO, 2009). Hence, treatment induced when the patient was admitted early to the hospital could have prevented the development of severe dengue and thus explain the steady low number of severe dengue cases per month even though the number of non-severe dengue cases fluctuated dramatically (Figure 2).

The single cluster detected at the end of the study year was not completely unexpected. Other studies report similar temporal clusters extending into the early months of the subsequent year since this time represents the rainy season in Malaysia (Aziz et al., 2012; Ling et al., 2014). However, the cluster found was different from other studies. The other studies were based on data obtained from district health departments, unlike our study which was hospital-based. In addition, our study was conducted much more recently than the others (Er et al., 2010; Ling et al., 2014). When adjusted for age, gender and race, this cluster (cluster A) consisted of five centroids in the time span of three months (October to December). The SIR observed for this cluster was 1.51 indicating that there was an excess of observed cases (23 cases) during this three-month period. Hence, there could be an outbreak of dengue cases between October and December in the following areas: Taman Cheras Utama, Cheras, Sri Bahtera, Pandan Perdana, Taman Bukit Permai, Bukit Pandan, Taman Seraya, Taman Muda, Taman Mawar, and Taman Putra that are all located south of Ampang Hospital. This location information could help first-aid responder services. Apart from gender, age and race, other covariates such as other demographic information, socioeconomic status and behavioural characteristics of the study population could also play a role affecting findings and possibly identify potential risk factor for the occurrence of the outbreak. With respect to potential limitations, deviation of coordinates from the actual resident of the patient could occur when the street level is used, particularly if there is a long road. However, the deviation should not be significant in our study because the majority of the roads within the centroids were short. Moreover, the random selection of coordinates along the road should not have altered the results significantly. Other limitation, such as population growth, could have affected the space-time permutation model if changes are not uniform throughout a study area. However, although our model did not include population data, the significance of population growth was negligible because the study only covered a single year. On the other hand, future studies employing a span of several years should consider changes in the population size.

The higher number of outbreaks at the end of the year detected among patients who visited Ampang Hospital, may be useful for hospital planning and management especially in allocating resources more effectively. Resources such as funding for treatment, manpower and the ambulance should be reserved for this possibility. However, the data need to be continuously analysed for a few years to be meaningful. Moreover, with a longer time of analysis, information useful for the prediction of outbreaks in the community served by the hospital may be found. The analysis can also be employed prospectively as the data are collected continuously.

\section{Conclusions}

The absence of clustered severe dengue cases may indicate that the occurrence of severe dengue cases may be spatio-temporally random in the population. However, the finding of increased number of general dengue cases during the three months at the end of the year should be useful in hospital planning and management. Prospective analysis might provide timely prediction of clustering of dengue cases. Emergency department may plan ahead in their emergency services including ambulance service.

\section{References}

Anno S, Imaoka K, Tadono T, Igarashi T, Sivaganesh S, Kannathasan S, Kumaran V, Surendran SN, 2015. Space-time clustering characteristics of dengue based on ecological, socioeconomic and demographic factors in northern Sri Lanka. Geospat Health 10:376.

Aziz S, Ngui R, Lim YAL, Sholehah I, Nur Farhana J, Azizan AS, Wan Yusoff WS, 2012. Spatial pattern of 2009 dengue distribution in Kuala Lumpur using GIS application. Trop Biomed 29:113-20.

Bhatt S, Gething PW, Brady OJ, Messina JP, Farlow AW, Moyes CL, Drake JM, Brownstein JS, Hoen AG, Sankoh O, Myers MF, George DB, Jaenisch T, Wint GRW, Simmons CP, Scott TW, Farrar JJ, Hay SI, 2013. The global distribution and burden of dengue. Nature 496:504-7.

Carabali M, Hernandez LM, Arauz MJ, Villar LA, Ridde V, 2015. Why are people with dengue dying? A scoping review of determinants for dengue mortality. BMC Infect Dis 15:301.

Chang AY, Parrales ME, Jimenez J, Sobieszczyk ME, Hammer SM, Copenhaver DJ, Kulkarni RP, 2009. Combining Google Earth and GIS mapping technologies in a dengue surveillance system for developing countries. Int J Health Geogr 8:49.

Coffey LL, Mertens E, Brehin AC, Fernandez-Garcia MD, Amara A, Després P and Sakuntabhai A, 2009. Human genetic determinants of dengue virus susceptibility. Microbes Infect 11:143-56.

Dean AG, Arner TG, Sunki GG, Friedman R, Lantinga M, Sangam S, Zubieta JC, Sullivan KM, Brendel KA, Gao Z, Fontaine N, Shu M, Fuller G, Smith DC, Nitschke DA, Fagan RF, 2011. Epi Info ${ }^{\mathrm{TM}}$, a database and statistics program for public health professionals. Centers for Disease Control and Prevention; Atlanta, Georgia.

Er AC, Rosli MH, Asmahani A, Mohamad Naim MR, Harsuzilawati M, 2010. Spatial mapping of dengue incidence: a case study in Hulu Langat District, Selangor, Malaysia. Int J Environ Chem Ecol Geol Geophys Engin 4:251-5.

Hafeez S, Amin M, Munir BA, 2017. Spatial mapping of temporal risk to improve prevention measures; a case study of dengue epidemic in Lahore. Spat Spatio-temporal Epidemiol 21:7785.

Hassan H, Shohaimi S, Hashim NR, 2012. Risk mapping of dengue in Selangor and Kuala Lumpur, Malaysia. Geospat Health 7:21-5.

Htun NSN, Odermatt P, Eze IC, Boillat-Blanco N, D'Acremont V, Probst-Hensch N, 2015. Is diabetes a risk factor for a severe clinical presentation of dengue? Review and meta-analysis. PLOS Negl Trop Dis 9:e0003741. 
Khor CC, Bich CTN, Pang J, Davila S, Long HT, Ong RTH, Dunstan SJ, Wills B, Farrar J, Van Tram T, Gan TT, Binh NTN, Tri LT, Lien LB, Tuan NM, Tham NTH, Lanh MN, Nguyet NM, Hieu NT, Van Vinh Chau N, Thuy TT.,Tan DEK, Sakuntabhai A, Teo YY, Hibberd ML, Simmons CP, 2011. Genome-wide association study identifies susceptibility loci for Dengue shock syndrome at MICB and PLCE1. Nat Genet 43:1139-41.

Kulldorff M, 2010. SaTScan user guide for version 9.0.

Ling CY, Gruebner O, Krämer A, Lakes T, 2014. Spatio-temporal patterns of dengue in Malaysia: combining address and subdistrict level. Geospat health 9:131-40.

Louis VR, Phalkey R, Horstick O, Ratanawong P, Wilder-Smith A, Tozan Y and Dambach P, 2014. Modeling tools for dengue risk mapping: a systematic review. Int J Health Geogr 13:50.

Malaysian Remote Sensing Agency (ARSM), Kementerian Sains Teknologi dan Inovasi (MOSTI) and Bahagian Kawalan Penyakit (BKP) Kementarian Kesihatan Malaysia (KKM), 2014. iDengue.

Available from: http://idengue.remotesensing.gov.my/idengue/ index.php (Accessed: 1 May 2017).

Rotela C, Lopez L, Frías Céspedes M, Barbas G, Lighezzolo A, Porcasi X, Lanfri MA, Scavuzzo CM, Gorla DE, 2017. Analytical report of the 2016 dengue outbreak in Córdoba city, Argentina. Geospat Health 12:564.

Soo KM, Khalid B, Ching SM, Chee HY, 2016. Meta-analysis of dengue severity during infection by different dengue virus serotypes in primary and secondary infections. PloS one 11:e0154760

WHO/TDR, 2012. Handbook for clinical management of dengue, WHO Press, pp 111.

World Health Organization, 2009. Dengue guidelines for diagnosis, treatment, prevention and control, WHO Press. pp 146.

World Health Organization (2015) Update on the Dengue situation in the Western Pacific Region. Available from:

http://www.wpro.who.int/emerging_diseases/dengue_biweekly_2 0150922.pdf. Accessed: 11 January 2018.

World Health Organization, 2016. Dengue and severe dengue. Available from: http://www.who.int/mediacentre/factsheets/ fs117/en/. Accessed: 27 March 2017. 